\title{
Celiac Disease Overview in Children by Focused on Iranian Studies
}

\author{
Pantea Tajik ${ }^{*}$ \\ Fellow of Pediatrics Gastroenterology, Mofid Hospital, Tehran, Iran \\ *Corresponding author: pantea_tajik2000@yahoo.com \\ Received October 05, 2014; Revised October 07, 2014; Accepted October 09, 2014

\begin{abstract}
In the past decade increased clinical awareness and improved tests has advanced owing to diagnosis of celiac disease in different parts the world. Celiac disease is now classified as common disorder which can present at any age with a wide-ranging of symptoms. The atypical presentations of celiac disease has increased over the past 2 decades and predominant in both adults and children. By now a gluten-free diet is the only method of celiac disease treatment. In this review article I have over viewed the celiac disease spectrum and present the different studies on celiac disease in children in Iran.
\end{abstract}

Keywords: celiac disease, gluten-free diet, associated disorders

Cite This Article: Pantea Tajik, “Celiac Disease Overview in Children by Focused on Iranian Studies.” International Journal of Celiac Disease, vol. 2, no. 4 (2014): 121-125. doi: 10.12691/ijcd-2-4-2.

\section{Introduction}

Celiac disease is a systemic immune-mediated disorder triggered by dietary gluten in genetically susceptible persons. Gluten is a protein complex found in wheat, rye, and barley. Celiac disease is characterized by a broad range of clinical presentations, a specific serum auto antibody response, and variable damage to the smallintestinal mucosa. Although the overall prevalence of celiac disease is $1 \%$ in the pediatric population, only $10-$ $15 \%$ of children with celiac disease has been diagnosed and treated $[1,2,3]$.

Celiac disease is defined by a characteristic of specific small intestinal biopsy lesions that is associated with nutrient malabsorption. With removal of gluten from the diet, prompt improvement in the biopsy appearance results, along with improved nutrient absorption [1,2].

The number of asymptomatic cases with positive serology and biopsy is 5 to 7 fold higher than typical symptomatic individuals exhibiting signs and symptoms including abdominal pain, growth retardation, short stature, chronic diarrhea, iron deficiency anemia that is refractive to treatment and intestinal lymphoma [3].

Serologic screening studies have shown that only a small proportion of cases of celiac disease are clinically recognized (21\% in a recent European study). The prevalence is 1.5 to 2 times as high among women as among men and is increased among persons who have an affected first-degree relative (10 to 15\%), type 1 diabetes (3 to 16\%), Hashimoto's thyroiditis $(5 \%)$ or other autoimmune diseases (including autoimmune liver diseases, Sjögren's syndrome, and IgA nephropathy), Down's syndrome (5\%), Turner's syndrome (3\%), and IgA deficiency (9\%) [1,2,3].
Genetic background plays a key role in the predisposition to the disease. The HLA-DQ2 haplotype (DQA $1 * 0501 / \mathrm{DQB} 1 * 0201$ ) is expressed in the majority of patients with celiac disease (90\%), whereas it is expressed in one third of the general population. In another $5 \%$ of patients with celiac disease, the HLA-DQ8 haplotype (DQA1*0301/DQB1*0302) is expressed, whereas almost all the remaining $5 \%$ of patients have at least one of the two genes encoding DQ2 (DQB1*0201 or DQA1*0501). DQ2 and DQ8 haplotypes expressed on the surface of antigen-presenting cells can bind activated (deamidated) gluten peptides, triggering an abnormal immune response. The DQ2 and DQ8 haplotypes are necessary but not sufficient for the development of celiac disease. So far, at least 39 non-HLA genes that confer a predisposition to the disease have been identified, most of which are involved in inflammatory and immune responses [2,3,4].

The pathogenesis of celiac disease involves an external trigger (gluten), changes in intestinal permeability, enzymatically modified gluten, HLA recognition, and innate and adaptive immune responses to gluten peptides involving self-antigens (e.g., transglutaminase), eventually leading to celiac enteropathy. Since gluten is pivotal in triggering this chain of events, a gluten-free diet is the cornerstone therapy for celiac disease $[3,4]$. In this review article I have over viewed the celiac disease spectrum and present the different studies on celiac disease in children in Iran.

\section{Typical and Atypical Presentation of Celiac Disease}

During the past few decades, the clinical presentation especially in children with celiac disease has been shift 
from typical symptoms (gastrointestinal) to atypical (intestinal and extra intestinal) symptoms. ”Typical” and "atypical" symptoms of celiac disease patients are mentioned in Table 1.

Table 1. Typical and atypical symptoms of celiac disease

\begin{tabular}{|l|l|}
\hline Typical symptoms & Atypical symptoms \\
\hline abdominal pain & fatigue \\
\hline diarrhea & dental enamel defects \\
\hline chronic & aphthous ulcers (canker sores) \\
\hline constipation & arthritis and arthralgias (joint pains) \\
\hline weight loss & low bone mineral density, fractures of bones \\
\hline vomiting & elevated liver enzymes \\
\hline Malabsorption & delayed puberty \\
\hline malnutrition & cerebellar ataxia \\
\hline iron deficiency anemia & recurring headaches \\
\hline dermatitis herpetiformis & peripheral neuropathy \\
\hline short stature & seizures \\
\hline abdominal distension & $\begin{array}{l}\text { psychiatric disorders, including anxiety, } \\
\text { panic attacks, depression }\end{array}$ \\
\hline
\end{tabular}

One of the atypical form of $\mathrm{CD}$ is eosinophilic esophagitis. During the last decade, the increasing prevalence of celiac disease and eosinophilic esophagitis has been recognized in pediatric and adult populations all over the world [5]. Case series have suggested an association between eosinophilic esophagitis and celiac disease. The prevalence of eosinophilic esophagitis in subjects with celiac disease was about 10-times that of the general population.

\section{Celiac Disease Screening}

Young children are likely to have false negative blood tests because the body has not had sufficient time to make the antibodies being tested. Then you should handle the right test according to the age of patients. Individuals should not start a gluten-free diet, the only treatment for celiac disease, before their evaluation including small intestinal biopsy (obtaining tissue samples) and serological examinations is completed [6].

While the tests for celiac disease are excellent for diagnosing the condition, false negative results can occur (tests are normal but disease is present). In very young children (under two years old) blood tests can be unreliable and may need to be repeated at later times. Biopsy may give false negative results if an insufficient number of biopsies were taken or biopsies were not taken at the correct locations or optimally handled by the laboratory receiving the tissue $[7,8]$. Also, patients already on a gluten-free diet may have negative test results because of partial treatment and in that case, endoscopy and biopsies would need to be repeated after restarting a gluten containing diet, usually for at least four weeks $[1,2,9]$.

Genetic screening, on the other hand, is not affected by age, testing methods or diet and can be an excellent tool. However, their main usefulness is to help exclude the diagnosis. That is, if the major genes associated with celiac disease are not present, one can exclude the diagnosis with close to $100 \%$ certainty [10].
These symptoms should go away over time once your child starts on a gluten-free diet. The duration of time can vary and it can take several months for the small intestine to completely heal itself after gluten is removed from the diet.

Growth failure in children with celiac disease is caused by the inability to absorb nutrients because of damage to the intestine. Once the damage recovers with initiation of the Gluten Free Diet, the absorptive functions of the intestinal tract will resume and growth will be restored. Depending on the age and pubertal status, most children will experience a catch up phase where their growth potential may be realized. However, older children who have passed puberty are unlikely to grow if their growth phase has ended [11-19].

Biopsy of the small intestine remains the standard for diagnosing celiac disease, and it should always be performed when clinical suspicion is high, irrespective of the results of serologic testing. Biopsy confirmation is crucial, given the lifelong nature of the disease and the attendant need for an expensive and socially inconvenient diet. Although no studies have examined the number of biopsies required for diagnosis, we believe that at least four to six endoscopic-biopsy specimens should be obtained from the duodenum, given the patchy nature of the disease and the difficulty of orienting the small pieces of tissue taken during biopsy for assessment of villous morphology [13-22]. Causes of villous atrophy other than celiac disease are shown in Table 2 [23,24,25].

Table 2. Causes of villous atrophy other than celiac disease

\begin{tabular}{|c|c|}
\hline \multicolumn{2}{|l|}{ Giardiasis } \\
\hline \multicolumn{2}{|l|}{ Collagenous sprue } \\
\hline \multicolumn{2}{|c|}{ Common-variable immunodeficiency } \\
\hline \multicolumn{2}{|l|}{ Autoimmune enteropathy } \\
\hline \multicolumn{2}{|l|}{ Radiation enteritis } \\
\hline \multicolumn{2}{|l|}{ Whipple's disease } \\
\hline \multicolumn{2}{|l|}{ Tuberculosis } \\
\hline \multicolumn{2}{|l|}{ Tropical sprue } \\
\hline \multicolumn{2}{|l|}{ Eosinophilic gastroenteritis } \\
\hline \multicolumn{2}{|c|}{ Human immunodeficiency virus enteropathy } \\
\hline \multicolumn{2}{|l|}{ Intestinal lymphoma } \\
\hline \multicolumn{2}{|l|}{ Zollinger-Ellison syndrome } \\
\hline \multicolumn{2}{|l|}{ Crohn's disease } \\
\hline \multicolumn{2}{|c|}{ Intolerance of foods other than gluten (e.g., milk, soy, chicken, tuna } \\
\hline \multicolumn{2}{|c|}{ Table 3. Fundamentals of the gluten-free diet } \\
\hline $\begin{array}{l}\begin{array}{l}\text { Grains that should be } \\
\text { avoided }\end{array} \\
\end{array}$ & $\begin{array}{l}\text { Wheat (includes spelt, kamut, semolina, } \\
\text { triticale), rye, barley (including malt) }\end{array}$ \\
\hline Safe grains (gluten-free) & $\begin{array}{l}\text { Rice, amaranth, buckwheat, corn, millet, } \\
\text { quinoa, sorghum, teff (an Ethiopian cereal } \\
\text { grain), oats }\end{array}$ \\
\hline $\begin{array}{l}\text { Sources of gluten-free } \\
\text { starches that can be used } \\
\text { as flour alternatives }\end{array}$ & $\begin{array}{l}\text { Cereal grains: amaranth, buckwheat, corn } \\
\text { (polenta), millet, quinoa, sorghum, teff, } \\
\text { rice (white, brown, wild, basmat,, } \\
\text { jasmine), montina (Indian rice grass) } \\
\text { Tubers: arrowroot, jicama, taro, potato, } \\
\text { tapioca (cassava, manioc, yucca) } \\
\text { Legumes: chickpeas, lentils, kidney beans, } \\
\text { navy beans, pea beans, peanuts, soybeans } \\
\text { Nuts: almonds, walnuts, chestnuts, } \\
\text { hazelnuts, cashews Seeds: sunflower, flax, } \\
\text { pumpkin }\end{array}$ \\
\hline
\end{tabular}


Nutritional therapy, the only accepted treatment for celiac disease, involves the lifelong elimination of wheat, rye, and barley from the diet. Clinical studies suggest that oats are tolerated by most patients with celiac disease and may improve the nutritional content of the diet and overall quality of life. However, oats are not uniformly recommended, because most commercially available oats are contaminated with gluten-containing grains during the growing, transportation, and milling processes [13,26,27,28,29] (Table 3) and reasons for poor adherence to a gluten-free diet are presented in Table 4.

Table 4. Reasons for poor adherence to a gluten-free diet are presented in

\begin{tabular}{|c|}
\hline High cost \\
\hline Poor availability of gluten-free products (in developing countries) \\
\hline Poor palatability \\
\hline Absence of symptoms when dietary restrictions not observed \\
\hline Inadequate information on gluten content of food or drugs \\
\hline Inadequate dietary counseling \\
\hline Inadequate initial information supplied by diagnosing physician \\
\hline Inadequate medical or nutritional follow-up \\
\hline Lack of participation in a support group \\
\hline $\begin{array}{l}\text { Inaccurate information from physicians, dietitians, support groups, or } \\
\text { Internet }\end{array}$ \\
\hline Dining out of the home \\
\hline Social, cultural, or peer pressures \\
\hline Transition to adolescence \\
\hline Inadequate medical follow-up after childhood \\
\hline $\begin{array}{l}\text { The following reasons are the main causes of poorly } \\
\text { response to the gluten free diet in celiac disease patients: } \\
\text { Incorrect diagnosis } \\
\text { Gluten ingestion (intentional or unintentional) } \\
\text { Microscopically colitis } \\
\text { Lactose intolerance } \\
\text { Pancreatic insufficiency } \\
\text { Bacterial overgrowth } \\
\text { Intolerance of foods other than gluten (e.g., fructose, } \\
\text { milk, soy) } \\
\text { Inflammatory bowel disease } \\
\text { Irritable bowel syndrome } \\
\text { Anal incontinence } \\
\text { Collagenous sprue } \\
\text { Autoimmune enteropathy } \\
\text { Refractory celiac disease (with or without clonal T cells) } \\
\text { Enteropathy-associated T-cell lymphoma. }\end{array}$ \\
\hline
\end{tabular}

\section{Iranian Studies on Celiac Disease}

In Several studies CD have been screened in high-risk populations. People at higher risk than normal individuals tend to have Down syndrome, Turner syndrome, selective IgA deficiency or other autoimmune diseases such as diabetes mellitus and dermatitis herpetiformis [22-28]. First-degree relatives of subjects with CD are also at a higher risk for CD [29]. The frequency of $C D$ in the general population depends upon the geographical area (environmental factors) and ethnicity (genetic factors). For instance; incidence of CD has been reported as high as $0.01 \%-0.5 \%$ and $1.2 \%$ of the total population in Sweden and England, respectively. Rates are higher in Arabian countries, with $0.5 \%-1.0 \%$ of the total population having CD $[6,7,8]$.

There have been on reports on the frequency of CD in Iran. This difference in prevalence suggests the presence of different risks in high-risk groups as well. Some other factors such as the higher incidence of consanguineous marriage in Middle Eastern countries may increase these frequencies significantly [14]. HLA typing is mainly used for diagnosing $\mathrm{CD}$ in cases with doubtful clinical, serologic, and histological findings. This can be performed by several methods, but it is costly and time consuming $[9,10,11]$.

Fifteen hundred school children, 6 to 12 years of age (Southern Iran) were screened in Shiraz for celiac disease through serological testing of their serum anti-tissue transglutaminase immunoglobulin antibodies (anti-tTG). A small intestinal biopsy was performed for children with positive serology tests and pathologic reports were given according to the modified Marsh classification [30]. Of the total students included, with a mean (SD) age of 9.5 years, 30 subjects had positive anti-tTG antibodies, resulting in a total seropositivity of $2 \%$. The prevalence of biopsy proven celiac disease (silent celiac) was $0.6 \%$. As in many other regions worldwide, this study estimated a relatively high prevalence of subclinical celiac disease in children in our area, citing the disease as an important health problem in our region [10].

In other study, children with Type one diabetes (T1D) following in diabetic clinic have been prospectively screened for CD, over a two-year period (2008-2010), by doing anti-TTG, EMA, and total IgA [11]. Children with positive anti-TTG titers (>50 U/ml) and/or EMA and children with persistently low positive anti-TTG titers (two readings 20-50 U/ml; within 6 months intervals) had upper endoscopy and 6 duodenal biopsies. One hundred and six children with T1D have been screened for CD: age ranged between 8 months to 15.5 years (62 females). Nineteen children had positive anti-TTG and/or EMA, however only 12 children had biopsy proven CD (11.3\%). Five of 12 had gastrointestinal symptoms (42\%). Children with T1D and CD had significantly lower serum iron than children with T1D alone $(8.5 \mu \mathrm{gm} / \mathrm{L}$ Vs. $12.5 \mu \mathrm{gm} / \mathrm{L} ; \mathrm{P}=$ $0.014)$. The sensitivity and specificity of anti-TTG were $91.6 \%$ and $93.6 \%$, with a positive and negative predictive value of $64.7 \%$ and $98.8 \%$, respectively.

In the study in Ahvaz city, 104 children (49 male, 55 female) with idiopathic short stature (ISS) without a specific etiology were studied. Extensive endocrine investigations had shown no abnormalities in any subject. Anthropometric parameters and IgA AGA and IgA TTG antibodies were evaluated in this study group. These antibodies were measured by enzyme-linked immunosorbent assay. All patients were referred for an endoscopic intestinal biopsy. The biopsy samples were classified according to modified Marsh classification [30].

Anti-tTG Ab were detected positive in 36 and IgA AGA in 35 patients. Thirty one Anti-tTG Ab positive and 28 IgA AGA positive subjects showed histological abnormalities compatible with celiac disease (33.6\%). Sensitivity, specificity, positive predictive value (PPV) and negative predictive value for IgA AGA were found to be $80 \%, 88.4 \%, 77.8 \%$ and $89.7 \%$, respectively. Sensitivity, specificity and PPV for IgA TTG antibodies were $88.6 \%$, 
94.2\% and $88.6 \%$, respectively. They concluded that the prevalence of celiac disease is high in patients with ISS and it is important to test all children with ISS for celiac disease by measuring serologic markers and performing an intestinal biopsy [8].

In the other study again in Ahvaz city prevalence of celiac disease in 30 siblings of 49 Iranian children with CD from 1999 to 2006 were reported. Siblings of confirmed celiac disease patients in this center were identified and enrolled in this study. Their serum immunoglobulin A and anti-tTG IgA/IgG were measured and multiple endoscopic duodenal biopsy specimens were obtained with parental consensus. A duodenal biopsy was performed in all 30 siblings. Clinical findings such as abdominal pain, fatigue, growth retardation and diarrhea were found in $53.3 \%$ of the completely studied siblings, and positive serology without histological changes was identified in four cases. Both serology and biopsy (confirmed new cases) were positive in 2 of the 30 siblings. The result of this study presence the high prevalence of celiac disease among siblings of patients with confirmed celiac disease and suggest that serologic screening in families having celiac disease is necessary. It is advantageous to diagnose the disease as soon as possible because early diagnosis and diet intervention may prevent serious complications such as growth retardation, short stature, chronic diarrhea, and malignancy [18].

\section{Conclusion}

Celiac disease occurs worldwide, with increasing prevalence in several countries consequently, the disease represents a growing public health problem and preventive strategies are warranted.

In this review article I founded that high prevalence of subclinical celiac disease in children, citing the disease as an important health problem in our region and it is important to test all children with idiopathic short stature, T1D and iron deficiency anemia for celiac disease by measuring serologic markers and performing an intestinal biopsy.

Due to high prevalence of celiac disease among siblings of patients with confirmed celiac disease necessitates serologic screening (and confirmatory biopsy if indicated) in families having celiac disease. Also I recommended to screening children with risk factor of celiac or have chronic disease like failure to thrive.

\section{References}

[1] Wang XQ, Liu W, Xu CD, et al. Celiac disease in children with diarrhea in 4 cities in China. J Pediatr Gastroenterol Nutr 2011; 53: 368-370.

[2] Rubio-Tapia A, Van Dyke CT, Lahe BD, et al. Predictors of family risk for celiac disease: a population-based study. Clin Gastroenterol Hepatol 2008; 6: 983-987.

[3] Mustalahti K, Catassi C, Reunanen A, et al. The prevalence of celiac disease in Europe: results of a centralized, international mass screening project. Ann Med 2010; 42: 587-595.

[4] Schuppan D, Yunker Y, Barisani D. Celiac disease: from pathogenesis to novel therapies. Gastroenterology 2009; 137: 1912-1933.

[5] Kabátová J. Epidemiology of Celiac Disease in Slovakia: Life Conditions of Celiac Disease Patients in Slovakia. International Journal of Celiac Disease 2014; 2: 38-39.
[6] Fasano A, Catassi C. Current approaches to diagnosis and treatment of celiac disease: an evolving spectrum. Gastroenterology 2001; 120: 636-651.

[7] Rostami-Nejad M, Romanos J, Rostami K, Ganji A, EhsaniArdakani MJ, Bakhshipour AR, Zojaji H, Mohebbi SR, Zali MR, Wijmenga C. Allele and haplotype frequencies for HLA-DQ in Iranian celiac disease patients. World J Gastroenterol 2014; 20 : 6302-6308.

[8] Jalal Hashemi, Eskandar Hajiani, H-Bb Shahbazin, Rahim Masjedizadeh, Navab Ghasemi. Prevalence of celiac disease in Iranian children with idiopathic short stature. ). World Journal of Gastroenterology 2009; 14: 7376-7380.

[9] Fallahi GH, Ahmadian JH, Rabbani A, Yousefnezhad AS, Rezaei N. Screening for celiac disease in diabetic children from Iran. Indian Pediatr 2010; 47: 268-270.

[10] Dehghani SM, Haghighat M, Mobayen A, Rezaianzadeh A, Geramizadeh B. Prevalence of celiac disease in healthy Iranian school children. World Journal of Gastroenterology /2010; 14: 7376-7382.

[11] Norris JM, Barriga K, Hoffenberg EJ, Taki I, Miao D, Haas JE, Emery LM, Sokol RJ, Erlich HA, Eisenbarth GS, Rewers M. Risk of celiac disease autoimmunity and timing of gluten introduction in the diet of infants at increased risk of disease. JAMA 2005; 293: 2343-2351.

[12] Revised criteria for diagnosis of coeliac disease. Report of Working Group of European Society of Paediatric Gastroenterology and Nutrition. Arch Dis Child 1990; 65: 909-911.

[13] Peter HR Green, and Christophe Cellier. Celiac Disease. N Engl J Med 2007; 357: 1731-1743.

[14] American Gastroenterological Association medical position statement: celiac sprue. Gastroenterology 2001; 120: 1522-1525.

[15] Yulia Treister-Goltzman, Roni Peleg. A Muslim Family with Several Members with Celiac Disease and Other Autoimmune Disorders. Journal of Immigrant and Minority Health 2013; DOI: 10.1007/s10903-013-9947-9

[16] Raivio T, Kaukinen K, Nemes E, et al. Self transglutaminasebased rapid coeliac disease antibody detection by a lateral flow method. Aliment Pharmacol Ther 2006; 24: 147-154.

[17] Catassi C, Fabiani E, Iacono G, et al. A prospective, double-blind, placebo-controlled trial to establish a safe gluten threshold for patients with celiac disease. Am J Clin Nutr 2007; 85: 160-166

[18] Chomeili B, Aminzadeh M, Hardani AK, Fathizadeh P, Chomeili $\mathrm{P}$, Azaran A. Prevalence of celiac disease in siblings of Iranian patients with celiac disease. Arq Gastroenterol. 2011; 48: 131-135.

[19] Rostami Nejad M, Aldulaimi D, Ishaq S, Ehsani-Ardakani MJ, Zali MR, Malekzadeh R, Rostami K. Geographic trends and risk of gastrointestinal cancer among patients with celiac disease in Europe and Asian-Pacific region. Gastroenterol Hepatol Bed Bench 2013; 6: 170-177.

[20] Samasca G, Sur G, Lupan L, Deleanu D. Gluten-free diet and quality of life in celiac disease. Gastroenterol Hepatol Bed Bench 2014; 7: 139-143.

[21] Fathi F, Ektefa F, Tafazzoli M, Rostami K, Rostami Nejad M, Fathi M, Rezaei-Tavirani M, Oskouie AA, Zali MR. The concentration of serum zinc in celiac patients compared to healthy subjects in Tehran. Gastroenterol Hepatol Bed Bench 2013; 6: 9295.

[22] Ehsani-Ardakani MJ, Fallahian M, Rostami K, Rostami-Nejad M, Lotfi S, Mohaghegh-Shalmani H, Dabiri R, Norouzinia M, Azizpour-Shoobi F, Zali MR. Celiac disease and dysfunctional uterine bleeding; the efficiency of gluten free diet. Bratisl Lek Listy 2014; 115: 19-21.

[23] Rostami-Nejad M, Haldane T, Aldulaimi D, Alavian SM, Zali MR, Rostami K. The role of celiac disease in severity of liver disorders and effect of a gluten free diet on diseases improvement. Hepat Mon 2013; 13: e11893.

[24] Rostami-Nejad M, Villanacci V, Hogg-Kollars S, Volta U, Manenti S, Reza-Zali M, Caio G, Giovenali P, Barakauskiene A, Kazenaite E, Becheanu G, Diculescu M, Pellegrino S, Magazzù G, Casella G, Di-Bella C, Decarli N, Biancalani M, Bassotti G, Rostami K. Endoscopic and histological pitfalls in the diagnosis of celiac disease: A multicentre study assessing the current practice. Rev Esp Enferm Dig 2013; 105: 326-333.

[25] Alavi Moghaddam M, Rostami Nejad M, Shalmani HM, Rostami K, Nazemalhosseini Mojarad E, Aldulaimi D, Zali MR. The effects of gluten-free diet on hypertransaminasemia in patients with celiac disease. Int J Prev Med 2013; 4: 700-704. 
[26] Ehsani-Ardakani MJ, Rostami Nejad M, Villanacci V, Volta U, Manenti S, Caio G, Giovenali P, Becheanu G, Diculescu M, Pellegrino S, Magazzù G, Casella G, Di Bella C, Decarli N, Biancalani M, Bassotti G, Hogg-Kollars S, Zali MR, Rostami K. Gastrointestinal and non-gastrointestinal presentation in patients with celiac disease. Arch Iran Med 2013; 16: 78-82.

[27] Rostami Nejad M. Celiac Disease and Non-Celiac Gluten Sensitivity; Evidences and Differences. International Journal of Celiac Disease 2013; 1: 6-7.
[28] Rostami Nejad M, Alavian SM. Celiac disease and abnormal liver function test. Int J Prev Med. 2012; 3: 745-746.

[29] Rostami Nejad M, Karkhane M, Marzban A, Nazemalhosseini Mojarad E, Rostami K. Gluten related disorders. Gastroenterol Hepatol Bed Bench 2012; 5: S1-7.

[30] Rostami K, Kerckhaert J, Tiemessen R, von Blomberg BM, Meijer JW, Mulder CJ. Sensitivity of antiendomysium and antigliadin antibodies in untreated celiac disease: disappointing in clinical practice. Am J Gastroenterol 1999; 94: 888-894. 